\title{
A dinâmica psíquica da criança em situação de acolhimento: um estudo de caso
}

\author{
Carolina de Fátima Tse* \\ Hilda Rosa Capelão Avoglia**
}

\begin{abstract}
Resumo
A relação entre a instituição que abriga e a criança acolhida, tema do presente estudo, teve como objetivo analisar a dinâmica psíquica da criança em situação de acolhimento. O estudo contou com a participação de uma menina de seis anos, acolhida há seis meses, diante da destituição dos pais, a criança encontrava-se disponível para a adoção. A participante foi submetida a entrevista semidiretiva e à aplicação do procedimento de Desenho-Estórias com Tema. Os dados obtidos foram analisados qualitativamente em uma perspectiva psicanalítica. Os resultados demostraram sentimentos de abandono e insegurança, diante dos quais predominam defesas como negação e isolamento, além de manifestações de comportamento agressivo, possivelmente para afastar-se do sofrimento emocional que vivencia. $\mathrm{O}$ estudo identifica ainda que, apesar das garantias legais oferecidas pelo abrigo, a participante mostra-se inibida diante dos contatos sociais e denota ausência de recursos internos para enfrentar o contexto no qual está inserida.
\end{abstract}

Palavras chave: Abrigo; Desenvolvimento; Avaliação.

\section{Abstract}

The relationship between the host institution and the sheltered child was the subject of the present research. The objective is to analyze the psychic dynamics of a child in a shelter. Participated of the study a six-years-old girl, sheltered for more than six months, faced with the dismissal of her parents, the child was available for adoption. The participant was submitted to a semi directional interview and the Drawings-Story procedure. Datas obtained were analyzed and systematized into a psychoanalytic perspective. The results showed feelings of abandonment and insecurity, and defenses such as denial and isolation, as well as demonstrations of aggressive behavior, used to move away from the emotional suffering that she has experienced. The study also identified that despite the legal guarantees offered by the shelter, the participant shows inability in social contacts and denotes absence of internal resources to face the context of emergency sheltering.

Key words: Shelter; Development; Evaluation.

* Mestranda em Psicologia da Saúde da Universidade Metodista de São Paulo.

**Profa. Dra. Universidade Metodista de São Paulo e Universidade Católica de Santos 


\section{Introdução}

O presente estudo apresenta como sustentação teórica os pressupostos do referencial psicanalítico, principalmente da escola inglesa, a fim de compreender a criança e os possíveis impactos em seu desenvolvimento quando se trata de ruptura dos vínculos maternos e familiares.

Segundo Klein (1970/1948) o Ego, é capaz de formar relações de objetos tanto na fantasia quanto na realidade, a partir do momento do nascimento. O bebê tem que lidar com o impacto da realidade, começando pela experiência de seu próprio nascimento e passando por inúmeras experiências de gratificação e frustração de seus desejos. Para a referida autora, no nascimento já existe Ego suficiente para experimentar ansiedade, usar mecanismos de defesa, mas apesar disso, não se trata de um Ego acentuado, como de um bebê de seis meses ou de um adulto plenamente desenvolvido, é uma estrutura ainda muito primitiva.

Nos primeiros tempos da infância manifestam-se ansiedades que obrigam o Ego a desenvolver mecanismos específicos de defesa. São essas ansiedades psicóticas e os mecanismos de defesas do Ego fundamentais que terão uma influencia profunda sobre o desenvolvimento (Klein, 1970/1948).

Nesse sentido, a autora supracitada enumera diversas defesas típicas de um Ego primitivo, como os mecanismos de divisão do objeto e os impulsos, idealização, negação da realidade externa e interna e a repressão de emoções, considerados mecanismos primitivos.

Quando existe uma situação traumática ou geradora de muita angústia, Freud (1923/2006) reconhece que o Ego é forçado a mobilizar mecanismos de defesa, assim sendo, Anna Freud (1946/1982), em concordância, considera que o enfrentamento dessa angústia e a mobilização dos mecanismos de defesa é uma forma que o Ego utiliza para ameniza-los. Anna Freud (1946/1982) estabelece que na infância o Ego tende a negar a fim de livrar-se do que lhe causa dor, angústia ou o que é indesejado, ao menos enquanto a comprovação da realidade ainda não estiver plenamente desenvolvida.

Ainda a respeito dos mecanismos de defesa, Anna Freud (1923/2006) postula que, no momento em que há uma excitação interna somada as representações psíquicas, suscita perigo, ou seja, um desequilíbrio do qual o Ego precisa proteger-se, então a defesa sobrevém na tentativa de preservá-lo e para tanto utiliza-se de mecanismos para preservar sua integridade.

Em relação à formação do Ego, Winnicott (1962) afirma que é primordial a presença da mãe de uma forma plena, para possibilitar o processo de maturação egóica, contudo se a mãe não puder desempenhar essa tarefa, o desenvolvimento egóico ocorre de forma distorcida.

Bowlby (1988) complemena essa reflexão ao defender que uma criança feliz, segura do amor da mãe, não fica extremamente angustiada, já a criança insegura, que tem dúvidas sobre o amor da mãe, fica facilmente sujeita a uma interpretação, por vezes errôneas dos fatos.

Ainda a respeito do desenvolvimento vincular do bebê, Aragão (2004) comenta que nos três meses iniciais de vida, o bebê ainda não tem desenvolvido aspectos físicos e psicológicos, $\mathrm{O}$ autor ressalta o sistema sensorial, a discriminação, o aparelho auditivo, a visão, enfim, a percepção ainda pouco desenvolvida, limita as experiências do bebê diante do afeto recebido, enfatizando com isso a importância da relação entre mãe e bebê, já que nessa dupla reside a possibilidade de dar forma ao psiquismo infantil.

Nesse momento é de extrema relevância compreender o contexto institucional, uma vez que a partir deste se situa o leitor no que se refere ao local no qual o estudo foi realizado, neste caso, uma casa de acolhimento institucional. Diversos autores pontuam a respeito das implicações do acolhimento na vida da criança.

Assim sendo, compreende-se que o serviço de acolhimento representa uma situação temporária para a criança e, justamente por esse caráter transitório, é provável que as relações estabelecidas sejam instáveis, como esclarece Justo (1997). Mesmo que as crianças tendam a buscar no outro a efetivação da figura materna (Souza, Karavisch \& Delaguardia, 2007) esse período ficará marcado por toda sua vida.

Bowlby (1982) esclarece que o desenvolvimento da criança em situação de acolhimento sofre danos significativos, tanto em aspectos físicos como psicológico. De acordo com o autor, é comum verificar nas crianças acolhidas problemas em estabelecer relações, dificuldades para resolução de problemas, apatia e falta de concentração na escola.

A criança institucionalizada, na perspectiva apresentada por Rizzinni (1995), mesmo recebendo cuidados de primeira necessidade, denota dificuldade em estabelecer vínculos significativos. A autora ressalta que abandonar uma criança ou enviá-la para o serviço de acolhimento a priva de ter uma família, com a qual deveria existir intimidade e cumplicidade. Para a referida autora não é possível estabelecer relações profundas em abrigos, considerando o elevado número de crianças em relação a quantidade de cuidadores. 
Nesse sentido, sentimentos como inveja e ciúmes nas crianças acolhidas podem ser despertados, desencadeando considerável agressividade, como explicam Anna Freud e Burlinghan (1944/1958). As autoras apontam três fases a este respeito, sendo que na primeira fase, as crianças não percebem o que seu ato hostil pode causar; na segunda fase, a criança começa a compreender o mal que causou, mas permanece indiferente; e, na terceira fase, ela se arrepende de seus atos.

Bowlby (1988) reforça que as crianças que vivem em instituições, podem ter seu desenvolvimento prejudicado pela ausência de relações com uma figura significativa, seja essa privação total ou parcial dos vínculos afetivos. Nesse sentido é provável que tais rupturas lhes desencadeiem angústia, necessidade de afeto de forma exacerbada e sentimentos de vingança, sendo que, por conta de tais sentimentos, suscite culpa.

As crianças acolhidas deveriam ter cuidadores preparados de tal forma a amenizar os impactos no seu desenvolvimento (Hetch \& Silva,2009). Os autores apontam a importância no investimento destes cuidadores, esperando que estas pessoas tentem suprir as necessidades afetivas das crianças.

Os cuidadores devem vincular-se as crianças tendo em vista seu desenvolvimento e questões como separações e perdas vividas, como argumenta Mendes (2007). O ambiente institucional não é o ideal para o desenvolvimento da criança, haja vista o atendimento padronizado, o grande número de crianças por cuidador, a falta de atividades planejadas e a fragilidade de redes de apoio social e afetivo (Carvalho, 2002).

\section{Método}

Trata-se de um estudo de caso que contou com a participação de uma menina, nomeada Alice $^{1}$, de seis anos de idade completos, em situação de acolhimento institucional superior há seis meses, em um abrigo na região metropolitana de São Paulo.

Com intuito de facilitar o contato com a criança, antes da aplicação do procedimento previsto no estudo, foi realizado um rapport, com objetivo de despertar o interesse da criança participante e aproximá-la das pesquisadoras, uma vez que, segundo Anastasi e Urbina (2000), o rapport é uma forma eficiente de obter cooperação e encorajar o sujeito da pesquisa, a fim de motivá-lo enquanto participante e potencialmente trazer informações da maneira mais satisfatória possível.

1 Nome fictício para preservar a identidade da participante.
Em seguida, optou-se pela entrevista semidiretiva, tendo em vista compreender a rotina da criança enquanto acolhida e suas manifestações diante da relação com o abrigo e com as cuidadoras.

O procedimento adotado para o estudo foi o Desenho-Estórias com Tema, seguindo a instrução: "Desenhe uma menina que mora em um abrigo". Na sequência, a criança foi orientada a contar do desenho produzido e, posteriormente, seguiu-se o inquérito.

Para a análise dos dados, considerou-se todos os componentes como um único processo, ou seja, foi necessário entender os desenhos, as histórias, o inquérito realizado como um todo, bem como sugere Trinca (1984; 1997).

No que tange aos aspectos éticos, vale ressaltar que o Termo de Consentimento Livre e Esclarecido (TCLE), assim como o Termo de Assentimento, foram apresentados à instiuição co-partipante e à criança, respectivamente, sendo que o presente estudo obteve parecer favorável pelo Comitê de Ética de Pesquisa da Universidade Metodista de São Paulo, sob Parecer no. 633.742.

\section{Resultados e Discussão}

Trata-se de Alice, uma menina de seis anos de idade, acolhida por abuso sexual, perpretado pelo pai. No momento da coleta dos dados se encontrava acolhida há onze meses e devido à destituição dos pais e disponível para adoção. Para a coleta dos dados foram necessários dois encontros em dias diferentes, pois no primeiro encontro, a menina desistiu da participação. Visando o cumprimento das exigências éticas, o procedimento foi interrompido, porém, conforme previsto, as pesquisadoras retornaram ao abrigo em outra ocasião e Alice decide retomar a participação.

\section{Primeiro Encontro}

"Alice desenha uma menina que mora em um abrigo", disse a pesquisadora. Alice comenta: "Você está falando de mim, né?", a aplicadora orientou que podia ser uma menina qualquer, que poderia desenhar da maneira que achasse melhor. A menina reclama que está com dores, a aplicadora sugere interromper a aplicação, a criança nega-se

Demonstrando pouca disponibilidade para participar do procedimento, conforme proposto, a criança reclama de dor na boca e na garganta, então se levanta, ameaça arremessar os lápis quando foi contida pelas pesquisadoras. Evidencia-se o desconforto de Alice, motivo que leva a interrupão do procedimento, sendo acompanhada até a área de convívio do abrigo. A menina chora, as pesquisadoras tentam acalmá-la, ela reage gritando. Alice é 
deixada na companhia da cuidadora, que não dá atenção às suas queixas dizendo: "Liga não, ela é assim, birrenta".

\section{Segundo Encontro}

Em outra oportunidade, Alice foi convidada a participar novamente da coleta de dados, ela aceita, dando-se continuidade ao procedimento, com a mesma consigna: "Desenha uma menina que mora em um abrigo".

Os materiais estavam dispostos na mesa, a menina atenta a falta de borracha e diz: "Eu falei pra você tražer borracha!", a respeito da disposição dos lápis: "Tá tudo errado!" organizando-os em fileira.

A participante insiste em não saber desenhar, a pesquisadora a incentiva, Alice grita: "Sai, eu sei desenhar". A aplicadora repete a instrução do procedimento e ela diz não saber fazer um abrigo, explica-se que pode ser da maneira como souber e achar melhor.

Durante a produção gráfica, Alice mantém-se em uma atitude negativa, demonstra insatisfação e agressividade: "Levanta Tia, quero ver seu tamanho", a aplicadora diz que ela pode desenhar como quiser. Alice repete: "Levanta tia, que en quero ver seu tamanho", a pesquisadora levanta e Alice diz: "É você que eu vou desenhar no abrigo!", usando de tom agressivo.

"Tia, você está pequenininha", comenta Alice enquanto desenha. Ela pede borracha, irritando-se porque não havia, conforme previsto nas orientações relativas ao material a ser disponibilizado para o procedimento. A menina fala, de maneira chorosa, que errou, que está faltando o braço, que precisa da borracha. A pesquisadora responde: "Eu não tenho, se você errou, en posso te dar outra folha". Alice recebe nova folha e a instrução é repetida novamente.

"Sempre os outros desenhar né?", "Eu não sei desenhar" e assim, por diversas vezes, reclamou durante a produção gráfica, contudo, não aceitava interromper o procedimento. Alice fêz diversos apontamentos negativos, sobre ter errado, não saber fazer e parecia indisposta diante da tarefa de desenhar.

"Eu preciso de borracha, se não tem, eu vou parar"!, a pesquisadora assente, considerando o desconforto da menina em participar, no entanto ela continua a produção. Alice entrega o desenho e diz não saber pintar, mas puxa a folha de volta: "Me dá, eu vou pintar o sapato". Quando diz não ter mais nada a acrescentar, a pesquisadora agradece, recebe e elogia o desenho. Desse modo, foram produzidos dois desenhos muito parecidos entre si.

A pesquisora: "Alice en gostaria que você contasse uma história desse desenho", a menina se mostra relutante, entretanto, após incentivos das pesquisadoras inicia: "Essa me- nina tava perdida e não tinha nada, pronto". Alice demonstra indisposição para continuar, mesmo assim continua: "Ela tinha um irmão grande. Irmão não, primo. Primo não. Ela não tem nada, ela só tem um bebê que crescen e não tinha mais nada. Ela tinha um filho grande que cresceu" Alice retoma: "Não, eu tô falando que ela tinha um irmão. Ela tinha casa. Ela tava perdida. Ela tava com as comidas na rua, com tudo na rua, foi comprar tudo no Carrefour. Ela tava perdida e eles ficaram na casa dela. Compron a casa dela. Roubo a casa dela", a respeito de quem roubou a casa, Alice diz: "Todo mundo".

Alice retoma: "O marido dela deixou ela sozinha na casa dele", a aplicadora questiona a respeito da vivência da personagem no abrigo, p: "E o que aconteceu com ela no abrigo?" Alice não responde e começa a cantar: "Tinha três cavalos no céu e ela foi lá pro céu. Tinha três cavalos no céu. Tia me ajuda a fazer um barco? ", a aplicadora constrói um barco de papel, Alice rejeita e fala rispidamente: "Não é assim!".

Nesse momento, por iminente desconforto da participante, a sessão foi interrompida, a menina intitula a estória: "A casa perdida".

\section{Análise integrada do material gráfico e verbal:}

A análise e interpretação, conforme descrito no método, segue as indicações de Trinca $(1984 ; 1997)$ que sugerem considerar para a análise as produções gráficas, as estórias e o inquérito, observando os movimentos gráficos e verbais, de maneira articulada.

Desde o rapport, Alice pareceu insatisfeita, desconfortável e incomodada, demonstrando irritabilidade, agressividade e indisponibilidade, possivelmente devido aos sentimentos despertados pela própria consigna do procedimento.

O título atribuído a história " $A$ casa vażia", parece apontar a relação de Alice com sua condição de acolhida, sendo que pode referir-se a si própria, ao abrigo, a uma casa vazia, que pode representar a si própria, como esvaziada, sem recursos internos para lidar como o que vivencia no cotidiano do espaço institucional.

Ao desenhar uma menina no abrigo, Alice diz que irá desenhar a pesquisadora quando lhe é solicitado que desenhe uma menina que mora em um abrigo, após a execução do desenho, diz: "Você está pequenininha tia", possivelmente buscando aproximar-se da pesquisadora e incluí-la em sua realidade.

"Essa menina tava perdida e não tinha nada, pronto", disse Alice a respeito da personagem, o indica sua identificação destacando os sentimentos de perda e abandono que acompanham a análise da verbalização, além da dificulda- 
de de elaborar esses sentimentos, pois expressa-se como se estivesse afastando-se do tema, ou seja, deslocando-se do conflito doloroso: "E acabou", "E pronto", quando recusa-se a contar a história.

A atitude de Alice, observada pelas pesquisadoras durante o procedimento é de inquietude, levantando-se diversas vezes e apoiando os pés na cadeira. O movimento expressado pela criança demonstra um potencial diagnóstico, ficar inquieta e sentar-se na beirada da cadeira, pode ser reconhecido como uma possível postura de fuga diante da situação, como sugere Hammer (1991). É possível reforçar essa ideia considerando a posição das figuras apresentadas, de maneira rígida e com os braços eretos ao longo do corpo, que podem significar, de acordo com mesmo autor, inquietude e desejo de fuga.

Ao ser questionada sobre a vivência da personagem no abrigo, Alice canta e fala de forma desconexa: "Tinha três cavalos no céu e ela foi lá pro céu. Tinha três cavalos no céu. Tia, me ajuda a fazer um barco?". Esse elemento parece reforçar o desejo de afastar-se da realidade que vivência, impulsionado pelo procedimento, que pareceu mobilizador, pois, Alice demonstra o desejo de interromper a participação, mas recusa-se. Parecia desfrutar a companhia da pesquisadora e a atenção individualizada que permeavam aquele momento, mas é possível pensar que quando não mais suporta, diz: "Eu to com dor na garganta", referendando a ideia de conflitos vivenciados pela menina.

Alice demonstrou em diversos momentos sinais de rigidez defensiva, buscando provavelmente valer-se de suas próprias ideias, desejos e regras, não aceitando as instruções. Ao sentir-se contrariada, reage gritando, batendo na mesa e falando de maneira ríspida, em determinado momento grita: "Não é assim, eu que vou achar pra você!", o que pode estar relacionado a necessidade de assegurar a própria identidade.

No que compreende o grafismo, as desproporções evidentes nas figuras humanas, como no tamanho da cabeça, tronco e membros, é um fato relevante para atentar a desarmonia na personalidade e no comportamento, conforme apresentado nos desenhos, seguindo as análises propostas por Van Kolck (1984).

Outros aspectos podem ser acrescidos, a medida em que se associam os elementos gráficos ao comportamento manifesto de Alice, pois demonstra, diversas vezes, postura imperativa, controladora e autoritária, frequentemente observada durante as aplicações: "Eu preciso de borracha, se não tem, eu vou parar!", "Eu falei pra você tražer".

Dessa maneira, é possível pensar que a rigidez apresentada é uma forma de controlar a agressividade, reativa e defensiva, entendendo que nos momentos em que Alice demonstra-se flexível consigo mesma, a agressividade vem à tona.

A rigidez na forma como verbaliza, a dificuldade de lidar com regras e de responder as instruções, podem ser identificadas durante o procedimento, dessa maneira os apontamentos supracitados corroboram com a interpretação de Buck (2003), uma vez que aponta representação de rigidez pela forma tensa que o braço é representado graficamente, ou seja, ao longo do corpo.

Nesse mesmo sentindo, Levy (1981) apontam que figuras que não demonstram movimento, revelam uma criança extremamente rígida e que apresenta conflitos profundos, no entanto, segundo o autor, as crianças buscam manter um controle rígido, contudo, em sua maioria, frágil.

Apesar desse comportamento, foi possível verificar que Alice fala com voz infantilizada e chorosa, em quaisquer momentos nos quais foi contrariada e, em geral, demonstrava agressividade. Desta forma, pode-se entender como um comportamento regredido e infantilizado, potencialmente para demonstrar fragilidade, além de igualmente demonstrar a necessidade de sentir-se mais aceita, contudo, ao não ser plenamente atendida em seus desejos, aumentava seu potencial agressivo.

Foi possível perceber em Alice, traços iminentes de agressividade e impulsividade. Durante o rapport, por diversas vezes, a menina falou alto, bateu na mesa, em um momento precisou ser contida para não arremessar os materiais gráficos dispostos sobre a mesa. Observa-se que Hammer (1991) explica que os desenhos projetivos, estão diretamente ligadas as necessidades pessoais que despontam por meio da criatividade gráfica, refletindo os sentimentos, nesse caso, a dolorosa situação de acolhimento.

Para Hammer (1991), é possível compreender que a ênfase que o indivíduo dá aos desenhos pode demonstrar muito a respeito do que lhe importa, e assim, pode afetar como a criança reage ao problema. Deste modo, é possível identificar a presença de elementos que apontam a extrema rigidez e agressividade da participante.

"Sai eu sei fazer", a menina fala alto e de forma ríspida por diversas vezes, sendo possível perceber em Alice momentos que a menina manifesta certa agressividade durante o procedimento. Tal afirmação pode ser reforçada quando Buck (2003) compreende a boca grande, conforme representada no desenho, implica tendências orais agressivas. Nesse mesmo sentido, Van Kolck (1984) considera que a boca, é um órgão de fi- 
xações precoces, linguagem indecente e crises de mau humor e intemperança.

$\mathrm{Na}$ produção gráfica, Alice solicita a borracha e irrita-se por não ser atendida. Ao ser questionada, a menina explica que não desenhou o braço, ao fazê-lo rejeita o desenho e recebe uma nova folha. De acordo com Van Kolck (1984), o braço faz referência ao contato com os objetos e pessoas, não desenhá-lo pode ser a representação da fraca ou inexistente relação de Alice com o outro. A ausência dos braços pode de acordo com Van Kolck (1984) representar um possível sentimento de inadequação e incapacidade de lidar com problemas representados pelas relações interpessoais, depressão extrema, afastamento, sentimento de extremo desamparo, abandono e necessidade de automutilação. Essa ideia analisada conjuntamente com a figura e a instrução: "Desenhe uma menina que mora em um abrigo" indica a dificuldade de Alice em se relacionar com os demais colaboradores do abrigo.

Van Kolck (1984) ressalta a forma como o tronco das figuras humanas e a linha de cintura como se apresentaram nos desenhos, demonstra a presença de impulsos insatisfeitos sentidos de forma aguda, rígida preocupação e policiamento de tais impulsos, reforçado por Buck (2003), que também argumenta que a ausência da mão, conforme apresentada nas produções gráficas da menina, refere-se à impulsividade.

É possível, por meio das produções gráficas observar elementos que apontam em Alice certo grau de retraimento, regressão, organicidade, preocupação consigo mesma, fixação no passado, impulsividade e necessidade de gratificação imediata (Buck, 2003). Tais aspectos nos permitem associar o comportamento de Alice à análise das produções gráficas, pois, Hammer (1991) ressalta que devem ser elementos analisados conjuntamente, de modo a entender que a postura apresentada é de grande valia para compreender o indivíduo em questão.

Possivelmente Alice tenta ocupar o lugar da pesquisadora, demonstrando ser uma posição mais desejada do que a que ela ocupa. Entende-se, dessa maneira, que a criança, nesse momento, sente-se ameaçada enquanto sujeito da pesquisa, pois provavelmente a temática do procedimento pode acarretar maior sofrimento, haja vista, que a instrução parece mobilizar a subjetividade vivida e sofrida da menina, e assim sendo, tenta afastar-se e defender-se desse desconforto trocando de lugar com a pesquisadora: "É você que en vou desenhar no abrigo" fala Alice para a pesquisadora.

Nota-se que a menina se recusa a falar da personagem em situações que envolvam o abrigo: "Tinha três cavalos no céu e ela foi lá pro céu. Tinha três cavalos no céu. Tia me ajuda a fazer um barco?" em uma evidente tentativa de não prosseguir, fazendo uso de mecanismos de defesa como negação, fuga e resistência.

Alice, apesar de conhecer e fazer parte do abrigo, não representa graficamente esse espaço institucional, nem mesmo no inquérito posterior, considerando-se que a consigna indicasse "Uma menina que mora no abrigo". A partir disso, é possível inferir que desviar da instrução, é mais uma vez, um indicativo de negação e resistência por parte de Alice.

Nos desenhos produzidos, o tamanho da cabeça fica em evidência, como tamanho grande em ambos desenhos, além das feições que apresentam traços agressivos e pouco amistosos, o que reforça a análise da dificuldade de Alice em se relacionar com o meio, uma vez que Van Kolck (1984), defende que a cabeça é o centro que reflete o próprio eu, o domínio social, o controle dos impulsos e as feições, por sua, vez expressam a necessidade do traço social da pessoa e suas formas de contato.

Van Kolck (1984) aponta também que, a maneira como a roupa é apresentada, pode refletir o ajustamento emocional da pessoa. Pessoas depressivas e que se isolam, segundo a autora, desenham a roupa da maneira como se apresentam Alice, ou seja, vestidos em formatos de triângulo, sem nenhum tipo de marcas corporais, que indica menor adequação à realidade.

O procedimento demonstra simbolicamente o sofrimento vivenciado e o uso de mecanismos de defesa em prol do Ego fragilizado. É possível identificar que Alice está experimentando sentimentos de abandono, solidão, menos valia e estado depressivo. Para Anna Freud $(1946 / 1982)$ os mecanismos de defesa são a forma do Ego para amenizar os conflitos dolorosos que o indivíduo possa estar enfrentando.

Por fim, percebe-se que a criança, parece vivenciar os prejuízos do acolhimento, conforme apresentado na pesquisa, seu desenvolvimento psíquico se mostra prejudicado, tornando-a ainda mais expostas ao contexto angustiante. Assim, considerando-se a fragilidade de egoica, compreende-se o uso dos mecanismos de defesa para amenizar o sofrimento desencadeado pela ruptura de vínculo e convivência no abrigo.

\section{Considerações finais}

As crianças reconhecidamente necessitam de cuidados, pois, nessa etapa, estão em pleno desenvolvimento de suas capacidades e da formação de sua subjetividade. No entanto, encaminhá-las ao abrigo, implica em privá- 
-las dos cuidados maternos, oferecendo-lhe cuidados padronizados, que visam questões de necessidades básicas como alimentação, frequência a escola, tratamentos de saúde, enfim, cuidados fundamentais à sua sobrevivência, entretanto, no que diz respeito ao desenvolvimento psicológico, identifica-se uma atenção insuficiente.

O estudo demonstrou os prejuízos psíquicos ao desenvolvimento desta criança, especialmente no que diz respeito a construção de sua subjetividade. Por meio da análise, foi possível considerar que a participante vivencia árduo sofrimento e experimenta sentimentos de abandono, solidão e menos valia, além de indicadores de estado depressivo.

Neste caso, especificamente, tais aspectos podem ser atribuidos não somente ao fato de tratar-se de uma criança em situação de acolhimento institucional, mas também a outros fatores, advindos de sua própria história de vida, antes do ingresso no abrigo, que potencializam os danos no percurso de seu desenvolvimento e merecem atenção na interpretação desse sofrimento.

Ao adentrarem a instituição, crianças negligenciadas e vitimizadas carecem de continência que abarque seu sofrimento, para lidarem com as situações traumáticas vivenciadas quando do rompimento da família de origem. Mesmo assim, aponta-se a importância de certa cautela quanto ao risco de possíveis generalizações dos resultados obtidos, uma vez que, o estudo limitou-se a singularidade de um caso clínico.

Assim sendo, considerou-se que o abrigo se apresenta como um espaço institucional que pouco atenua o sofrimento das crianças, contrapondo-se a sua natureza e finalidade, ou seja, acolher. Nesse sentido, o abrigo mostra-se falho no que tange os aspectos afetivos e emocionais inerentes ao desenvolvimento das crianças.

Dessa maneira, partindo-se da análise de Alice, é possível que perceber que a menina parece não se reconhecer, nem aceitar ser parte desse espaço, pois ao representar sua convivência no abrigo, faz uso da fantasia compensatória e negando sua dolorosa condição de acolhida.

\section{Referências Bibliográficas}

Anastasi, A; Urbina, S. (2000). Testagem psicológica. Porto Alegre: Artes Médicas Sul.

Aragão, R.O. (2004). O bebê, o corpo e a linguagem. São Paulo: Casa do Psicólogo. Bowlby, J. (1988). Cuidados maternos e saúde mental. São Paulo: Martins Fontes.

Bowlby, J. (1982). Formação e rompimento dos laços afetivos. São Paulo: Martins Fontes.

Buck, J. N. (2003). H-T-P: Casa-árvore-pessoa- Técnica projetiva de desenho: manual e guia de interpretação. São Paulo: Vetor.

Carvalho, A. (2002). Crianças institucionalizadas e desenvolvimento: possibilidades e desafios. In: Lordelo, E; Carvalho, A; Koller, S.H. Infância brasileira e contextos de desenvolvimento. São Paulo: Casa do Psicólogo, p.19-44.

Freud, Anna (1946/1982). O ego e os mecanismos de defesa. Rio de Janeiro: Civilização Brasileira.

Freud, S. (1923/2006). O Ego e o ID. in: Obras Completas de Sigmund Freud. Rio de Janeiro: Imago, v.19, p. 7-48

Hammer, E.F.(1991). Aplicações clínicas dos desenhos projetivos. São Paulo: Casa do Psicólogo.

HETCH, B; SILVA, R. F. P. Crianças institucionalizadas: a construção psíquica a partir da privação do vínculo materno. Portal dos Psicólogos, Rio Grande do Sul, 2009. Disponível em:<http://www.psicologia.pt/ artigos/textos/TL0199. pdf>. Acesso em: 02 de maio de 2015.

Justo, J. S. (1997). A institucionalização vivida pela criança de orfanato. In: A. Merisse; J. S. Justos; L.C. Rocha; M.S. Vasconcelos (Orgs). Lugares da infância: reflexões sobre a história da criança na fábrica, creche e orfanato. São Paulo: Artes \& Ciência, p.53-69.

Klein, M. (1948/1970). Contribuições à Psicanálise. São Paulo: Mestre Jou.

Levy, S. (1981). Desenho da figura humana. In: Hammer, E.F. (Org) Aplicações clínicas dos desenhos projetivos. Rio de Janeiro: Interamericana, p. 61-58.

MENDES, C.L.P.C. Vinculos e rupturas na adoção: do abrigo para a família adotiva. Instituto de Psicologia, Universidade de São Paulo, São Paulo, 2007. Disponível em file:///C:/Users/69203p.UMESPACAD.001/Downloads/ Mendes Mestrado.pdf Acesso em: 02 de maio de 2015.

Rizzini, I. (1995). A Arte de governar crianças: a história das políticas sociais, da legislação e da assistência à infância no Brasil. Rio de Janeiro: Instituto Interamericano Del Niño.

Sousa, I.F. C; Karavisch, M.G.S. F; Delaguardia, V.L. (2007). A formação de vinculos em crianças abrigadas. Faculdade de Psicologia e Fonoaudiologia, Universidade Metodista de São Paulo, São Bernardo do Campo.

Trinca, W. (1984/1997). Diagnóstico psicológico: a prática clínica. São Paulo: EPU.

Van Kolck, O. L. (1984). Testes projetivos gráficos no diagnóstico psicológico. São Paulo: EPU.

Winnicott, D. W. (1962). O ambiente e os processos de maturação: estudos sobre a teoria do desenvolvimento emocional. Porto Alegre: Artmed.

Submetido em: 10-2-2017

Aceito em: 29-8-2017 